\title{
Treating adult scoliosis and back pain with the SpineCor Pain Relief Back Brace J McAviney* and T Pappas
}

\author{
Address: The London Scoliosis Clinic UK \\ Email: J McAviney* - jebmcaviney@gmail.com \\ * Corresponding author
}

\author{
from 6th International Conference on Conservative Management of Spinal Deformities \\ Lyon, France. 21-23 May 2009 \\ Published: 14 December 2009 \\ Scoliosis 2009, 4(Suppl 2):O67 doi:I0.I I86/I748-7|6I-4-S2-O67
}

This abstract is available from: http://www.scoliosisjournal.com/content/4/S2/O67

(c) 2009 McAviney and Pappas; licensee BioMed Central Ltd.

\section{Objective}

The main objective of this study was to explore the issues of treating adult scoliosis and pain by conservative means. We present two case studies of different types of adult scoliosis successfully managed with the SpineCor brace.

\section{Background}

Management of pain in adult scoliosis represents a significant clinical challenge. Both adolescent scoliosis in the adult (ASA) and degenerative de-novo scoliosis (DDS) can cause significant pain. Over recent years, the SpineCor brace has been used by practitioners in the treatment of painful adult scoliosis. To date, SpineCor has been used clinically in adult treatment in hundreds of cases, and the empirical results seem positive.

\section{Methods and results}

Patient A, a 26 year old female with painful ASA, had pain prior to SpineCor treatment that averaged 7/10 (10 being the worst). Using the SpineCor brace daily for 8 to 12 hours for 3 months, she had a gradual improvement of her pain to an average of 1-2/10. The initial x-ray showed a $32^{\circ}$ right thoracic scoliosis. In the SpineCor brace 1 month after fitting, the x-rays showed an improvement of $8^{\circ}$ to $24^{\circ}$. Her pain relief $(1-2 / 10)$ and spinal correction have been maintained for over 2 years by using the SpineCor brace part-time. Patient B, a 47 year old female with a DDS, had pain prior to treatment that averaged 8/10. In the SpineCor brace, she had an immediate relief of her pain to $3 / 10$. The initial $x$-ray showed a $40^{\circ}$ degenerative lumbar scoliosis curve. In the SpineCor brace, $\mathrm{x}$-rays showed an improvement of $7^{\circ}$ to $33^{\circ}$ in her curve. Her pain relief (0-3/10) and spinal correction have been maintained for over 2 years by using the SpineCor brace daily. Also of note is the improved left lateral shift showing "spinal off loading".

\section{Outcome}

Both patients achieved significant pain reduction over a 2 year period, demonstrating that in these cases, the SpineCor brace has been an effective treatment for pain related to ASA and DDS.

\section{Conclusion}

Prospective research in a large population is required to determine the overall effectiveness of the SpineCor brace, but early results seem positive. 